\title{
Práticas de Enfermagem nas salas de vacina da Atenção Básica
}

\author{
Nathalia de Souza Monezi, Dalvani Marques.
}

\section{Resumo}

Objetivo: mapear e comparar as atividades desenvolvidas pelas auxiliares e técnicas de enfermagem na sala de vacina. Método: Estudo quanti-qualitativo, os dados secundários de um banco sobre atividades realizadas na Atenção Básica por 150 auxiliares e técnicas de enfermagem de Campinas/SP e coletados através do método sombra e entrevistas em salas de vacinas de três Centros de Saúde, foram analisados de acordo com sua natureza. Resultados: O perfil das auxiliares e técnicas de enfermagem era, em sua maioria, de mulheres, casadas e com filhos. Atualmente, as atividades desenvolvidas nas salas de vacina são executadas pelas técnicas de enfermagem, a exceção das campanhas de vacinação, nas quais as duas categorias participam. O trabalho in loco nas salas de vacina demonstrou que existe uma diferença entre os períodos manhã e tarde avaliados, o que demonstra uma quebra da continuidade da rotina das salas de vacinas previstas no PNI. Conclusão: Atualmente, a história do PNI está sendo escrita por mais uma categoria da enfermagem, as técnicas de enfermagem, demonstrando mais uma vez a força de trabalho, a eficiência e o compromisso da Enfermagem nas salas de vacina na Atenção Básica.

\section{Palavras-chave:}

Atenção Básica, Programas de imunização, Papel do Profissional de Enfermagem.

\section{Introdução}

Atualmente, o Brasil conta com uma enfermagem separada por categorias. Podemos dizer que através dessa massa trabalhadora, o Brasil é considerado um dos países mais comprometidos com a imunização da população-alvo, conquista sendo afirmada desde a implantação o Programa Nacional de Imunização (PNI) em 1973. Hoje a imunização da população está sob responsabilidade dos municípios na Atenção Básica, portanto, a vacina, o vacinador e a população são responsáveis por esse processo.

Os objetivos deste estudo foram de mapear e comparar as atividades desenvolvidas pelas auxiliares e técnicas de enfermagem na sala de vacina.

\section{Resultados e Discussão}

Estudo quanti-qualitativo, realizado em duas etapas. A primeira etapa analisou dados secundários de um banco com informações sobre atividades na sala de vacina realizadas na Atenção Básica por 150 auxiliares e técnicas de enfermagem de Campinas/SP. A segunda etapa, através do método sombra e de entrevistas, analisou o trabalho in loco realizado em salas de vacinas de três Centros de Saúde.

O perfil das auxiliares e técnicas de enfermagem eram, em sua maioria, de mulheres, casadas e com filhos. As auxiliares de enfermagem trabalham a mais de 11 anos no serviço, enquanto as técnicas de enfermagem atuam a menos de 10 anos.

Foram analisadas nove atividades: Avaliação da situação vacinal, Aplicação de vacinas, Orientação quanto ao tipo de imunobiológico, reações esperadas e efeitos adversos, Controle de estoque de imunobiológicos, Controle de rede de frio, Solicitação de imunobiológicos, Participação em campanhas de vacinação, Ações de vigilância epidemiológica e Levantamento de perfil epidemiológico da população adscrita junto com a equipe de saúde.

Atualmente, as atividades desenvolvidas nas salas de vacina estão sendo executadas pelas técnicas de enfermagem, a exceção das campanhas de vacinação, nas quais todas participam.

O trabalho in loco nas salas de vacina demonstrou que existe uma diferença entre os períodos manhã e tarde, o que pode indicar uma quebra da continuidade na rotina das salas de vacinas previstas no PNI.

Tabela 1. Atividades realizadas em salas de vacina em Campinas/SP

\begin{tabular}{|c|c|c|c|}
\hline Atividades realizadas & $\begin{array}{l}\text { CENTRO DE } \\
\text { SAÚDE } 1\end{array}$ & $\begin{array}{l}\text { CENTRO DE } \\
\text { SAÚDE } 2\end{array}$ & $\begin{array}{l}\text { CENTRO DE } \\
\text { SAÚDE } 3\end{array}$ \\
\hline Controle da temperatura da geladeira? & SIM & SIM/NÃ̃O & SIM \\
\hline Como foi a abordagem do profissional? & ÓTIMA/BOA & RUIM/BOA & BOA \\
\hline Realizada lavagem das mãos? & $\operatorname{sim}$ & SIM/NÃO & $\operatorname{siM}$ \\
\hline $\begin{array}{l}\text { Informação sobre os eventos adversos? } \\
\text { De quanto em quanto tempo é feita } \\
\text { terminal da sala de vacina? }\end{array}$ & $\begin{array}{c}\text { SIM } \\
\text { QUINZENAL }\end{array}$ & $\begin{array}{l}\text { SIM/NÃO } \\
\text { QUINZENAL }\end{array}$ & $\begin{array}{l}\text { NÃ̃o } \\
\text { NÃO } \\
\text { REALIZADA }\end{array}$ \\
\hline $\begin{array}{l}\text { Durante o procedimento, o profissional } \\
\text { exerceu o objetivo de garantir a máxima } \\
\text { segurança na administração de } \\
\text { imunobiológico? }\end{array}$ & SIM & SIM & SIM \\
\hline
\end{tabular}

Entretanto, in loco notou-se a complexidade das atividades desenvolvidas pela equipe de enfermagem para garantir a máxima segurança na administração de imunobiológicos, prevenir infecção cruzada, proporcionar conforto e segurança aos usuários.

\section{Conclusões}

Atualmente, a história do PNI está sendo escrita por mais uma categoria da enfermagem, as técnicas de enfermagem, demonstrando mais uma vez a força de trabalho, a eficiência e o compromisso da Enfermagem nas salas de vacina na Atenção Básica.

\section{Agradecimentos}

Agradeço ao PIBIC pela oportunidade de ampliar meus conhecimentos. À Prof ${ }^{a}$ Dalvani pela orientação e paciência e ao Juliano pelo companheirismo.

1 Paim J, Travassos C, Almeida C, Bahia L, Macinko J. O sistema de saúde brasileiro: história, avanços e desafios. The Lancet 2011; 377(9779):1778-1797.

2 Brasil. Lei n.7498/86, de 25 de junho de 1986. Conselho Federal de Enfermagem. Regulamentação do exercício da Enfermagem e de outras providencias [Acesso em 27 mar 2017]. Disponível em: http://www.cofen.gov.br/lei-n-749886de-25-de-junhode-1986 4161.html 